\title{
Sodium oxybate therapy provides multidimensional improvement in fibromyalgia: results of an international phase 3 trial
}

\author{
Michael Spaeth, ${ }^{1}$ Robert M Bennett, ${ }^{2}$ Beverly A Benson, ${ }^{3}$ \\ Y Grace Wang, ${ }^{3}$ Chinglin Lai, ${ }^{3}$ Ernest $\mathrm{H}$ Choy ${ }^{4}$
}

- An additional supplementary table is published online only. To view this file please visit the journal online (http://ard.bmj.com/ content/71/6.toc).

${ }^{1}$ Rheumatologische Schwerpunktpraxis, Gräfelfing, Germany

${ }^{2}$ Fibromyalgia Research Unit, Oregon Health and Science University, Portland, Oregon, USA

3Jazz Pharmaceuticals, Palo Alto, California, USA

${ }^{4}$ Cardiff University School of Medicine, Cardiff, UK

\section{Correspondence to \\ Michael Spaeth, \\ Rheumatologische \\ Schwerpunktpraxis, \\ Bahnhofstrasse 95, Gräfelfing, \\ Munich 82166, Germany; \\ dr.spaeth@mac.com}

Received 6 July 2011

Accepted 29 November 2011

Published Online First

31 January 2012

\begin{abstract}
Background Fibromyalgia is characterised by chronic musculoskeletal pain and multiple symptoms including fatigue, multidimensional function impairment, sleep disturbance and tenderness. Along with pain and fatigue, non-restorative sleep is a core symptom of fibromyalgia. Sodium oxybate (SXB) is thought to reduce non-restorative sleep abnormalities. This study evaluated effects of SXB on fibromyalgia-related pain and other symptoms.
\end{abstract}

Methods 573 patients with fibromyalgia according to 1990 American College of Rheumatology criteria were enrolled at 108 centres in eight countries. Subjects were randomly assigned to placebo, SXB $4.5 \mathrm{~g} / \mathrm{night}$ or SXB $6 \mathrm{~g} / \mathrm{night}$. The primary efficacy endpoint was the proportion of subjects with $\geq 30 \%$ reduction in pain visual analogue scale from baseline to treatment end. Other efficacy assessments included function, sleep quality, effect of sleep on function, fatigue, tenderness, healthrelated quality of life and subject's impression of change in overall wellbeing.

Results Significant improvements in pain, sleep and other symptoms associated with fibromyalgia were seen in SXB treated subjects compared with placebo. The proportion of subjects with $\geq 30 \%$ pain reduction was $42.0 \%$ for SXB4.5 $\mathrm{g} / \mathrm{night}(\mathrm{p}=0.002)$ and $51.4 \%$ for SXB6 $\mathrm{g} /$ night $(\mathrm{p}<0.001)$ versus $26.8 \%$ for placebo. Quality of sleep (Jenkins sleep scale) improved by 20\% for SXB4.5 g/night ( $\mathrm{p} \leq 0.001)$ and 25\% for SXB6 $\mathrm{g} / \mathrm{night}$ $(p \leq 0.001)$ versus $0.5 \%$ for placebo. Adverse events with an incidence $\geq 5 \%$ and twice placebo were nausea, dizziness, vomiting, insomnia, anxiety, somnolence, fatigue, muscle spasms and peripheral oedema.

Conclusion These results, combined with findings from previous phase 2 and 3 studies, provide supportive evidence that SXB therapy affordsimportant benefits across multiple symptoms in subjects with fibromyalgia.

Chronic musculoskeletal pain is common, and causes distress and reduced quality of life. ${ }^{1}$ Patients with chronic musculoskeletal pain frequently experience unrefreshing sleep, ${ }^{2}$ and while it seems logical to assume that pain leads to disturbed sleep, there is increasing evidence that dysfunctional sleep leads to hyperalgesia and allodynia. ${ }^{3-6}$ These symptoms are the prototypical features of fibromyalgia and formed the basis for the 1990 diagnostic criteria promulgated by the American College of Rheumatology (ACR). ${ }^{7}$ Based on these ACR criteria, fibromyalgia has a population prevalence of $2-5 \%$ and incurs substantial medical costs. ${ }^{89}$ While fibromyalgia is defined in terms of pain, ${ }^{7}$ most patients are multisymptomatic, with core outcome domains that include pain, fatigue, multidimensional function, sleep disturbance, patient global impression of change (PGIC) in condition and tenderness. ${ }^{10}$

Polysomnographic studies in fibromyalgia patients typically report non-refreshing sleep associated with abnormal polysomnographic findings-in particular, alpha intrusion and reduced slow-wave sleep (SWS). ${ }^{11}$ Furthermore, Moldofsky et al ${ }^{12}$ showed that fibromyalgia-like symptoms could be induced in healthy normal volunteers by the deprivation of stage 4 (N3) sleep. There is also increasing evidence that 'non-restorative' sleep and its influence on peripheral functions promotes hyperalgesia, fatigue and bodily hypersensitivity. ${ }^{510}$ Although the detailed mechanisms underlying sleep problems in fibromyalgia are not known, given that epidemiological evidence suggests that the attainment of restorative sleep resolves chronic widespread pain, ${ }^{13}$ it is reasonable to hypothesise that sleep disturbance is a fundamental component of fibromyalgia pathophysiology, and the amelioration of sleep disturbance may be clinically beneficial to fibromyalgia patients.

Sodium oxybate (SXB) is the sodium salt of $\gamma$-hydroxybutyrate, an endogenous compound found in the central nervous system and a metabolite of $\gamma$-aminobutyric acid. The drug is approved in the USA, Canada and Europe for the treatment of symptoms in narcolepsy.

SXB is thought to improve the quantity and quality of SWS. ${ }^{14}$ Previously, Scharf et a ${ }^{15}$ observed that some narcoleptic subjects with co-existing fibromyalgia experienced a reduction of pain and fatigue while being treated with SXB. They conducted a small placebo-controlled study using polysomnography and reported that SXB reduced pain and fatigue in subjects with fibromyalgia and dramatically reduced non-restorative sleep abnormalities ( $\alpha$ intrusion and decreased SWS) associated with fibromyalgia. ${ }^{16}$ More recently, a larger, phase 2, placebo-controlled trial reported beneficial effects of two dosages of SXB ( 4.5 or $6 \mathrm{~g}$ ) on multiple symptoms in patients with fibromyalgia, and the SXB $6 \mathrm{~g}$ dose improved sleep physiology as measured by polysomnography. ${ }^{17}{ }^{18}$ In addition, the first large, multicentre, phase 3, placebo-controlled trial conducted in the USA demonstrated clinically important benefits of SXB on multiple symptoms in subjects with fibromyalgia. ${ }^{19}$ 
This paper reports the results of a second phase 3 , randomised, double-blind, placebo-controlled trial that evaluated the efficacy and safety of SXB in fibromyalgia patients from the USA and seven European countries.

\section{METHODS}

\section{Study design and subjects}

This double-blind, placebo-controlled, parallel-group study examined the efficacy and safety of SXB $4.5 \mathrm{~g} / \mathrm{night}$, SXB $6 \mathrm{~g} /$ night and placebo in fibromyalgia subjects. The study consisted of a screening and washout/withdrawal period, a baseline week, a 14-week randomised treatment and a post-treatment followup. Subjects were enrolled from February 2007 to April 2009 at 108 study centres in eight countries (France, Germany, Italy, The Netherlands, Poland, Spain, UK and USA). Women or men aged 18 years or over had to meet the ACR criteria for fibromyalgia, ${ }^{7}$ have a body mass index less than $40 \mathrm{~kg} / \mathrm{m}^{2}$, and have an average score of 50 or greater on a $100-\mathrm{mm}$ pain visual analogue scale (VAS) at baseline. Subjects had to discontinue medications, herbal remedies and/or devices that might influence outcome; non-pharmacological treatments for fibromyalgia needed to remain unchanged, and only paracetamol (acetaminophen) was allowed as rescue medication. Subjects with a body mass index of $35 \mathrm{~kg} / \mathrm{m}^{2}$ or greater and less than $40 \mathrm{~kg} / \mathrm{m}^{2}$ had to have polysomnography at screening to rule out obstructive sleep apnoea (OSA). Subjects with OSA had to be on stable continuous positive airway pressure (CPAP) for 30 days prior to baseline and continue CPAP for the study duration.

Potential subjects were excluded if they had any painful disorder other than fibromyalgia and/or any medical or psychiatric condition that might compromise study participation (including current major depressive disorder and generalised anxiety disorder). They were also excluded if they had a current or previous substance-use disorder, including alcohol abuse; had previously taken $\gamma$-hydroxybutyrate or SXB; or had previously participated in clinical trials with SXB.

This study was conducted in compliance with the Declaration of Helsinki, International Conference on Harmonisation Guidelines for Good Clinical Practice, the US Code of Federal Regulations and Directives of the European Parliament and was approved by the ethics committee or institutional review board at every study site. All participants provided written informed consent.

\section{Procedures}

During screening, eligibility evaluations included assessment for sleep apnoea by clinical judgement, assisted by the Berlin questionnaire, or polysomnography to rule out OSA. ${ }^{20}$ All screened subjects on any prohibited medications underwent a washout for up to 30 days. At baseline, eligible subjects were issued electronic diaries (PHT Corporation, Charlestown, Massachusetts, USA) to rate their current pain and fatigue three times a day (morning, afternoon and evening) on a VAS ranging from 0 (none) to $100 \mathrm{~mm}$ (worst imaginable) throughout the following week and to record rescue medication use.

Subjects who met all eligibility criteria and demonstrated competency using the diary were randomly assigned to receive an oral solution of SXB $4.5 \mathrm{~g} / \mathrm{night}$, SXB $6 \mathrm{~g} /$ night, or placebo matched to active-treatment volume. The randomisation code was generated using permuted blocks (block size of six) and implemented centrally by an interactive voice-response system. Treatment assignment remained blinded until the study database was locked and ready for analysis. Subjects randomly assigned to SXB $6 \mathrm{~g} /$ night received SXB $4.5 \mathrm{~g} /$ night during the first 2 weeks and then SXB 6 g/night for the remaining 12 weeks. All study medication was taken nightly in two equal doses, one at bedtime and the second $2.5-4 \mathrm{~h}$ later. ${ }^{21}$ Subjects discontinuing early were followed for an additional 2 weeks.

\section{Study outcomes \\ Efficacy}

Assessments were based on recommendations of the 9th Working Group of Outcome Measures in Rheumatology Clinical Trials (OMERACT), which includes measurement of tenderness and questionnaires on the domains of pain, fatigue, multidimensional function, sleep disturbance and global impression of change. ${ }^{10}$

\section{Primary endpoint}

The primary efficacy endpoint was the proportion of subjects recording $30 \%$ or greater reduction in pain VAS scores from the average baseline week value to the average final treatment week (week 14) value.

\section{Secondary endpoints}

Secondary efficacy parameters included mean change from baseline in fatigue VAS scores; the proportion of subjects with a $30 \%$ or greater reduction on the fibromyalgia impact questionnaire (FIO) total score; ${ }^{22}$ sleep assessment using the Jenkins sleep scale (JSS), a validated measure of sleep quality; ${ }^{23} 24$ health-related quality of life based on the Medical Outcomes Study 36-item short-form health survey (SF-36); ${ }^{25}$ and the EuroQol-5 dimensions (EQ-5D) self-report questionnaire, comprising five aspects of quality of life and overall health state. ${ }^{26}$ Overall impression of wellbeing was evaluated by subjects using the PGIC, and the impact of daytime sleepiness and tiredness on activities of daily living was evaluated by subjects using the functional outcomes of sleep questionnaire (FOSQ) ${ }^{27}$ The proportion of subjects meeting composite response measures was also determined. Fibromyalgia composite responders were predefined as subjects who had $30 \%$ or greater reduction in pain, a PGIC response of 'much better' or 'very much better' and a $30 \%$ or greater reduction in FIO total score. The FIQ has 10 domains: pain, fatigue, sleep, physical function, work, general health, participation, stiffness, anxiety and depression. Functional composite responders were defined as subjects who had $30 \%$ or greater reduction in pain, a PGIC response of 'much better' or 'very much better', plus improved SF-36 scores using two cutoffs-scores of 5 or greater and scores 6 or greater. Clinician assessments included tenderness using the manual tender point survey (MTPS), ${ }^{28}$ with a tender point count and tender point index and the clinician global impression of change. ${ }^{29}$

The number needed to treat (NNT) and its 95\% CI were estimated as a post-hoc analysis for pain reduction $(30 \%, 50 \%$ and $80 \%)$ and improvement in FIQ (14\% and $30 \%)$.

\section{Tolerability and safety}

All observed or spontaneously reported treatment-emergent adverse events (AE) were determined by prespecified criteria and recorded. Physical findings, including vital signs, were also recorded, and 12-lead electrocardiograms were performed (at screening and at the end of the treatment period). Clinical laboratory tests (haematology, chemistry and urinalysis) were performed at screening, week 4 and the end of the treatment period.

\section{Statistical analyses}

Efficacy was assessed in the intent-to-treat population. For continuously distributed outcomes, the mean change in an active-treatment group (SXB 4.5 g/night or SXB 6 g/night) was 


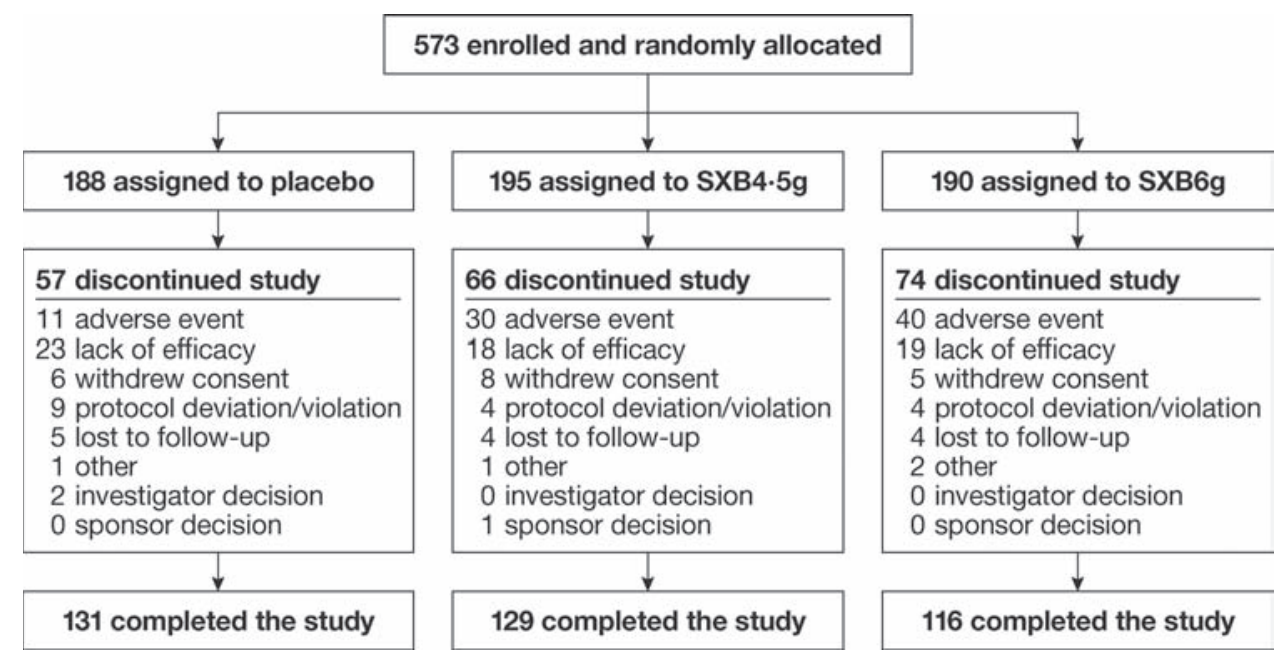

Figure 1 Subject disposition. SXB4.5g, sodium oxybate $4.5 \mathrm{~g} / \mathrm{night}$. SXB6g, sodium oxybate $6 \mathrm{~g} / \mathrm{night}$.

Table 1 Baseline demographic and clinical characteristics of the study population*

\begin{tabular}{|c|c|c|c|c|}
\hline Characteristic & Placebo $(n=188)$ & SXB4.5g $(n=195)$ & SXB6g $(n=190)$ & Total $(\mathrm{N}=573)$ \\
\hline Age, years & $46.8(9.7)$ & $46.6(10.8)$ & $46.4(11.6)$ & $46.6(10.7)$ \\
\hline Female, $\mathrm{n}(\%)$ & $168(89.4)$ & $175(89.7)$ & $170(89.5)$ & $513(89.5)$ \\
\hline \multicolumn{5}{|l|}{ Race, $\mathrm{n}(\%)$} \\
\hline White & $173(92.0)$ & $182(93.3)$ & $169(88.9)$ & $524(91.4)$ \\
\hline Black & $10(5.3)$ & $11(5.6)$ & $18(9.5)$ & $39(6.8)$ \\
\hline Other & $5(2.7)$ & $2(1.0)$ & $3(1.6)$ & $10(1.7)$ \\
\hline Body mass index, $\mathrm{kg} / \mathrm{m}^{2}$ & $27.4(4.7)$ & $27.4(4.3)$ & $28.0(4.8)$ & $27.6(4.6)$ \\
\hline Time since first fibromyalgia symptoms, years, mean (SD) & $9.3(7.9)$ & $9.9(8.8)$ & $9.9(9.5)$ & $9.7(8.8)$ \\
\hline Time since first fibromyalgia diagnosis, years, mean (SD) & $5.1(6.3)$ & $5.1(5.5)$ & $4.4(5.0)$ & $4.9(5.6)$ \\
\hline Previous pharmacological treatment for fibromyalgia, $\mathrm{n}(\%)$ & $182(96.8)$ & $185(94.9)$ & $182(95.8)$ & $549(95.8)$ \\
\hline Previous non-pharmacological treatment for fibromyalgia, $\mathrm{n}(\%)$ & $132(70.2)$ & $128(65.6)$ & $138(72.6)$ & $398(69.5)$ \\
\hline \multicolumn{5}{|l|}{ Baseline scores } \\
\hline Pain VAS (scale 0-100) & $72.6(12.9)$ & $70.5(13.0)$ & $72.2(14.0)$ & $71.8(13.3)$ \\
\hline Fatigue VAS (scale 0-100) & $73.5(15.0)$ & $71.1(15.4)$ & $71.5(17.2)$ & $72.0(15.9)$ \\
\hline TPC (scale 0-18), median (range)† & $18.0(8,18)$ & $18.0(11,18)$ & $18.0(12,18)$ & $18.0(8,18)$ \\
\hline TPI (scale 0-72) & $39.5(12.2)$ & $37.9(11.7)$ & $38.2(11.4)$ & $38.6(11.7)$ \\
\hline MTPS (scale 0-180) & $111.3(33.3)$ & $112.3(32.4)$ & $109.2(30.9)$ & $111.0(32.2)$ \\
\hline FIO total score (scale 0-100) & $63.7(14.1)$ & $62.3(15.2)$ & $62.1(15.1)$ & $62.7(14.8)$ \\
\hline SF-36 PCS (scale 0-100) & $29.1(7.9)$ & $29.6(8.7)$ & $30.8(7.5)$ & $29.8(8.1)$ \\
\hline EQ-5D overall health state & $46.6(22.95)$ & $48.8(22.25)$ & $47.4(24.00)$ & $47.6(23.06)$ \\
\hline JSS total score (scale 0-20), median (range) $^{\dagger}$ & $16.0(3,20)$ & $16.0(0,20)$ & $16.0(2,20)$ & $16.0(0,20)$ \\
\hline FOSQ (scale 5-20) & $13.4(3.8)$ & $13.4(3.8)$ & $13.7(3.8)$ & $13.5(3.8)$ \\
\hline CGIS (scale 1-7) & $4.3(1.1)$ & $4.5(1.0)$ & $4.4(1.0)$ & $4.4(1.0)$ \\
\hline
\end{tabular}

*Except when indicated otherwise, values are mean $( \pm S D)$.

†Median values are presented due to skewed distribution of data.

CGIS, clinical global impression of severity; EQ-5D, EuroQol-5 dimensions self-report questionnaire; FIQ, fibromyalgia impact questionnaire; FOSQ, functional outcomes of sleep questionnaire; JSS, Jenkins sleep scale; MTPS, manual tender point survey; PCS, physical component summary; SD, standard deviation; SF-36, Medical Outcomes Study 36-item short-form health survey; SXB4.5g, sodium oxybate $4.5 \mathrm{~g} / \mathrm{night;}$ SXB6g, sodium oxybate $6 \mathrm{~g} / \mathrm{night}$; TPC, tender-point count; TPI, tender-point index; VAS, visual analogue scale.

compared with that for placebo using analysis of variance models adjusted for site and treatment-group-by-site interaction. If the $p$ value for an interaction exceeded 0.1 , the term was dropped from the model. For binary outcomes, a $\chi^{2}$ test was used to compare the proportion of responders (percentage of subjects achieving a prespecified change) in an active-treatment group with placebo. All outcomes were assessed by last observation carried forward. In addition, all outcomes were assessed using the prespecified baseline observation carried forward method. Statistical analysis was performed using SAS version 9.1 for Windows, and all testing was two-sided with a significance level of $5 \%$. Post-hoc correlation analyses using Pearson's correlation coefficient were performed between the FIQ subscale 7 (measure of restorative sleep) and pain VAS, fatigue VAS, global assessments and JSS total score. In addition, a post-hoc analysis using Pearson's correlation coefficient was conducted between the changes in the JSS and FOSQ total scores with the changes in pain VAS, FIO total score, PGIC and fatigue VAS. Finally, a post-hoc analysis was conducted of the proportion of subjects with a $14 \%$ or greater reduction in the FIO total score, which is the minimal clinically important difference (MCID) in the FIO.

All subjects who received at least one dose of study medication (SXB or placebo) were included in the safety analysis. AE, including serious AE, were coded using the Medical Dictionary for Regulatory Activities (MedDRA, version 9.1). Treatmentemergent $\mathrm{AE}$ were defined as events with onset, worsened severity or increased intensity on or after the date of randomisation and through the day after the last dose of study drug. 
Subjects were counted once for maximum severity of an event, preferred term and system organ class.

The sample size of 525 subjects was planned based on data from an earlier study to provide at least $90 \%$ power to detect a target treatment difference in the primary endpoint for one dose of SXB based on $\chi^{2}$ tests with a significance level of $5 \%$.

\section{RESULTS}

\section{Study subjects and baseline characteristics}

A total of 573 subjects was randomly assigned and 376 subjects (65.6\%) completed the study (figure 1). Although early discontinuations due to lack of efficacy occurred more frequently with placebo compared with SXB $4.5 \mathrm{~g} / \mathrm{night}$ or SXB $6 \mathrm{~g} / \mathrm{night}$, the differences were less marked than for early discontinuations due to $\mathrm{AE}$, which occurred in more subjects on SXB $4.5 \mathrm{~g} /$ night or SXB $6 \mathrm{~g} /$ night than on placebo (figure 1).

Baseline characteristics were well balanced across treatment groups; the majority of subjects were white and female (table 1). The mean baseline clinical global impression of severity score of 4.4 indicated moderately severe illness, and other baseline averages indicated clinically significant pain, fatigue, sleep impairment and impaired functionality.

\section{Efficacy}

Pain

During 14 weeks of treatment, pain was reduced with both SXB doses relative to placebo when assessed by multiple pain parameters. At week 14, the proportion of subjects with $30 \%$ or greater reduction in pain VAS, the primary efficacy endpoint, was significantly greater with SXB $4.5 \mathrm{~g} /$ night $(42 \%, \mathrm{p}=0.002)$ and SXB $6 \mathrm{~g} /$ night $(51.4 \%, \mathrm{p}<0.001)$ versus placebo $(26.8 \%$; table 2$)$. Similarly, the proportion of subjects with $50 \%$ or greater reduction in pain VAS was significantly greater with both doses of SXB versus placebo $(p \leq 0.003)$, and $80 \%$ or greater reduction in pain VAS was significantly greater with SXB $6 \mathrm{~g} / \mathrm{night}$ versus placebo ( $\mathrm{p}=0.003$; table 2). Significant reductions in pain VAS were observed as early as week 1 and persisted through week 14 (figure 2A), indicating that pain reduction was rapid and sustained.

Categorical outcomes were analysed using the $\chi^{2}$ test. Continuous outcomes were analysed using analysis of variance with treatment and centre as the factors. Interaction of centre by treatment was included if it was significant $(p<0.1)$.

\section{Tenderness}

Significant differences were observed in MTPS for SXB $4.5 \mathrm{~g} / \mathrm{night}$ and SXB $6 \mathrm{~g} /$ night and in tender-point count and tender-point index for the SXB $4.5 \mathrm{~g} /$ night group only versus placebo (table 2).

\section{Fatigue}

For both SXB doses, there were significant reductions in fatigue versus placebo (table 2). These decreases were observed as early as week 1 and persisted through week 14, suggesting rapid and sustained improvement (figure 2B).

\section{Multidimensional function}

Post-hoc analysis of the FIQ using the MCID of $14 \%$ or greater reduction in the total score ${ }^{30}$ showed that significantly greater proportions of subjects reported clinically important differences with both SXB doses versus placebo $(p<0.001$; table 2$)$. In a preplanned analysis, when a more stringent criterion of $30 \%$ or greater reduction in the FIO total score was used to define moderate/good responders, significantly greater proportions of subjects in the SXB groups met the criterion versus placebo ( $p<0.001$; table 2$)$. Mean changes in total FIQ scores from
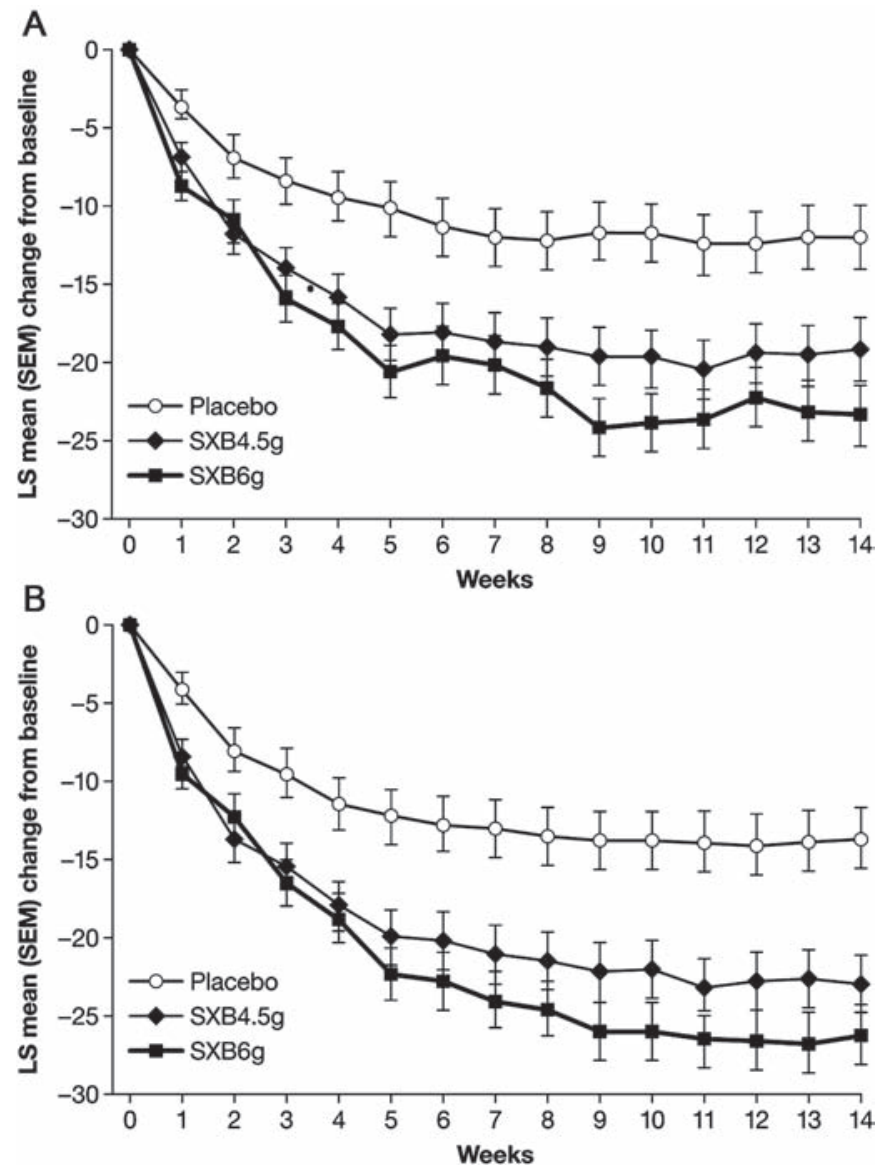

Figure 2 (A) Change from baseline in mean pain VAS score over time (ITT population, LOCF analysis). (B) Change from baseline in mean fatigue VAS score over time (ITT population, LOCF analysis). Note: error bars $=S E M$. ITT, intent to treat; LOCF, last observation carried forward; LS, least squares; SEM, standard error of LS mean; SXB4.5g, sodium oxybate $4.5 \mathrm{~g} / \mathrm{night}$; SXB6g, sodium oxybate $6 \mathrm{~g} / \mathrm{night}$; VAS, visual analogue scale.

baseline were significantly greater for both SXB doses versus placebo as early as week 1 and continued to week 14 ( $p<0.001$ at all time points). The proportion of responders on the fibromyalgia syndrome composite score was significantly greater for SXB $4.5 \mathrm{~g} /$ night $(\mathrm{p}=0.005)$ and SXB $6 \mathrm{~g} /$ night $(\mathrm{p}<0.001)$ versus placebo. Analysis of the functional composite score based on the lower cut-off for SF-36 scores ( 25$)$ demonstrated that significantly greater proportions of subjects treated with SXB $4.5 \mathrm{~g} /$ night $(\mathrm{p}=0.004)$ and SXB $6 \mathrm{~g} /$ night $(\mathrm{p}<0.001)$ showed significant clinical improvement versus placebo. Using an SF-36 cut-off of 6 , the functional composite score showed that significantly greater proportions of subjects were responders with SXB $4.5 \mathrm{~g} /$ night $(\mathrm{p}=0.004)$ and SXB $6 \mathrm{~g} /$ night $(\mathrm{p}<0.001)$ versus placebo.

Significantly greater increases in the SF-36 physical component summary score were observed for SXB $4.5 \mathrm{~g} / \mathrm{night}$ $(\mathrm{p}=0.002)$ and $\mathrm{SXB} 6 \mathrm{~g} /$ night $(\mathrm{p}=0.003)$ versus placebo, indicating a beneficial effect of SXB on physical functioning. Numerically greater increases in the EQ-5D overall health state scores were also observed for both SXB doses versus placebo.

\section{Sleep}

A significant improvement in sleep quality was observed by changes from baseline in JSS scores for SXB $4.5 \mathrm{~g} /$ night and SXB $6 \mathrm{~g} /$ night versus placebo $(\mathrm{p}<0.001)$. Improvements in functionality 
Table 2 Changes in outcome variables from baseline to endpoint in subjects with fibromyalgia after blinded treatment with $4.5 \mathrm{~g}$ or $6 \mathrm{~g}$ sodium oxybate, compared with placebo*

\begin{tabular}{|c|c|c|c|c|c|}
\hline \multirow[b]{2}{*}{ Outcome } & \multirow{2}{*}{$\begin{array}{l}\text { Placebo } \\
(n=188)\end{array}$} & \multicolumn{4}{|c|}{ Sodium oxybate } \\
\hline & & $4.5 \mathrm{~g}(\mathrm{n}=195)$ & p Value vs placebo & $6 g(n=190)$ & p Value vs placebo \\
\hline \multicolumn{6}{|l|}{ Pain and tenderness } \\
\hline \multicolumn{6}{|l|}{ Pain VAS } \\
\hline \multicolumn{6}{|l|}{$\mathrm{n}(\%)$ of responders } \\
\hline$\geq 30 \%$ criteria & $49(26.8)$ & $81(42.0)$ & 0.002 & $94(51.4)$ & $<0.001$ \\
\hline$\geq 50 \%$ criteria & $28(15.3)$ & $54(28.0)$ & 0.003 & $69(37.7)$ & $<0.001$ \\
\hline$\geq 80 \%$ criteria & $11(6.0)$ & $22(11.4)$ & NS & $29(15.8)$ & 0.003 \\
\hline Pain VAS (change in score from baseline) & $-11.9 \pm 2.0$ & $-19.2 \pm 2.0$ & 0.010 & $-23.4 \pm 1.9$ & $<0.001$ \\
\hline \multicolumn{6}{|l|}{ Tender point } \\
\hline TPC (change in score from baseline), median (range) $†$ & $0(-16,5)$ & $0(-16,4)$ & 0.003 & $0(-17,4)$ & NS \\
\hline TPI (change in score from baseline) & $-5.5 \pm 1.0$ & $-9.1 \pm 1.0$ & 0.007 & $-7.8 \pm 1.0$ & NS \\
\hline MTPS (change in score from baseline) & $-14.1 \pm 2.6$ & $-27.9 \pm 2.6$ & $<0.001$ & $-21.7 \pm 2.6$ & 0.036 \\
\hline \multicolumn{6}{|l|}{ Sleep and fatigue } \\
\hline Fatigue VAS (change in score from baseline) & $-13.7 \pm 1.9$ & $-23.0 \pm 1.9$ & $<0.001$ & $-26.2 \pm 1.9$ & $<0.001$ \\
\hline JSS (change in score from baseline), median (range) $†$ & $-1.0(-20,7)$ & $-4.0(-18,8)$ & $<0.001$ & $-5.0(-20,5)$ & $<0.001$ \\
\hline FOSO (change in score from baseline) & $1.0 \pm 0.3$ & $2.1 \pm 0.3$ & 0.003 & $2.1 \pm 0.3$ & 0.004 \\
\hline \multicolumn{6}{|l|}{ Functionality and HROOL } \\
\hline \multicolumn{6}{|l|}{ FIO (total score) } \\
\hline \multicolumn{6}{|l|}{$\mathrm{n}(\%)$ of total FIQ responders } \\
\hline$\geq 14 \%$ criteria & $79(43.6)$ & $119(62.6)$ & $<0.001$ & $131(70.8)$ & $<0.001$ \\
\hline$\geq 30 \%$ criteria & $54(29.8)$ & $95(50.0)$ & $<0.001$ & $102(55.1)$ & $<0.001$ \\
\hline Total FIO (change in score from baseline) & $-9.9 \pm 1.5$ & $-19.2 \pm 1.5$ & $<0.001$ & $-20.6 \pm 1.5$ & $<0.001$ \\
\hline \multicolumn{6}{|l|}{ SF-36 } \\
\hline PCS (change in score from baseline) & $3.6 \pm 0.7$ & $6.4 \pm 0.7$ & 0.002 & $6.3 \pm 0.7$ & 0.003 \\
\hline \multicolumn{6}{|l|}{ EQ-5D overall health state } \\
\hline $\mathrm{EQ}-5 \mathrm{D}$ (change in score from baseline) & $5.1 \pm 2.2$ & $9.2 \pm 2.2$ & NS & $10.6 \pm 2.2$ & NS \\
\hline \multicolumn{6}{|l|}{ Global impression of change } \\
\hline PGIC responders $\ddagger \mathrm{n}(\%)$ & $29(16.0)$ & $61(32.1)$ & $<0.001$ & $71(39.7)$ & $<0.001$ \\
\hline CGIC responders§n (\%) & $34(18.7)$ & $68(35.4)$ & $<0.001$ & $69(37.5)$ & $<0.001$ \\
\hline \multicolumn{6}{|l|}{ Composites } \\
\hline Fibromyalgia composite responders $\uparrow \mathrm{n}(\%)$ & $21(13.7)$ & $42(26.6)$ & 0.005 & $53(34.0)$ & $<0.001$ \\
\hline Functional composite responders ${ }^{*} \mathrm{n}(\%)$ & $15(9.8)$ & $34(21.7)$ & 0.004 & $40(26.0)$ & $<0.001$ \\
\hline
\end{tabular}

\footnotetext{
*Except when indicated otherwise, values are the least squares mean \pm SEM.

†Median values are presented due to skewed distribution of data.

‡Proportion of subjects who responded 'very much better' or 'much better'.

$\S$ Proportion of subjects whose disease was rated 'very much improved' or 'much improved' by the investigator.

IIncludes pain VAS ( $\geq 30 \%$ reduction), FIO total score ( $\geq 30 \%$ reduction) and PGIC responders ('very much better' or 'much better').

**Includes pain VAS ( $\geq 30 \%$ reduction), PGIC ('very much better' or 'much better') and SF-36 PCS ( $\geq 6$ increase) responders.

CGIC, clinical global impression of change; EQ-5D, EuroOol-5 dimensions self-report questionnaire; FIO, fibromyalgia impact questionnaire; FOSO, functional outcomes of sleep

questionnaire; HROOL, health-related quality of life; JSS, Jenkins sleep scale; MTPS, manual tender point survey; NS, not statistically significant; PCS, physical component summary;

PGIC, patient global impression of change; SEM, standard error of least squares mean; SF-36, Medical Outcomes Study 36-item short-form health survey; TPC, tender-point count;

TPI, tender-point index; VAS, visual analogue scale.
}

related to sleep, as measured by mean changes from baseline in FOSQ scores, were also significantly greater for SXB $4.5 \mathrm{~g} / \mathrm{night}$ $(\mathrm{p}=0.003)$ and SXB $6 \mathrm{~g} /$ night $(\mathrm{p}=0.004)$ versus placebo.

In post-hoc analyses, there were strong correlations between the FIO subscale 7 , which is a subjective measure of restorative sleep ('tired upon awakening'; responses ranging from 0 indicating 'awoke well rested' to 10 indicating 'awoke very tired'), and pain VAS ( $r=0.68 ; p<0.001)$, fatigue VAS ( $r=0.78 ; p<0.001)$, global assessments (PGIC, $\mathrm{r}=0.59 ; \mathrm{p}<0.001$ ) and JSS total score $(r=0.56 ; p<0.001)$. Strong correlations were also demonstrated between changes from baseline in pain VAS and fatigue VAS $(\mathrm{r}=0.84 ; \mathrm{p}<0.001)$ and between the change in pain VAS and function (FIO total score; $r=0.78 ; \mathrm{p}<0.001$ ).

In addition, post-hoc analyses demonstrated a statistically significant association between the changes in sleep measures (JSS and FOSQ) and the changes in other clinical outcomes (pain VAS, FIO total score, PGIC fatigue VAS). These associations were of moderate strength, with the highest correlation coefficient between the sleep measures and multidimensional function (FIO). These data are presented in a supplementary table, available online only.

\section{Global impression of change}

Significantly greater proportions of subjects reported feeling 'much better' or 'very much better' at week 14 by PGIC with SXB $4.5 \mathrm{~g} /$ night and SXB $6 \mathrm{~g} /$ night versus placebo (both $\mathrm{p}<0.001$; table 2). Similarly, significantly greater proportions of subjects in both SXB groups versus placebo (both $p<0.001$ ) had their condition rated as 'very much improved' or 'much improved' by investigators using the clinical global impression of change (table 2).

\section{Number needed to treat}

Table 3 shows the NNT for pain reduction and improvement in FIO. The NNT represents the number of patients who would need to be treated with SXB for one additional patient to improve over the number of patients who would improve if placebo had been used. For all levels of pain reduction and multidimensional function, numerically fewer patients would need to be treated with SXB 6 g/night to obtain an improvement.

For all efficacy endpoints, results consistent with the last observation carried forward analysis were observed with the baseline observation carried forward analysis (data not shown). 
Table 3 NNT for improvement in pain and multidimensional function estimated in a post-hoc analysis

\begin{tabular}{lll}
\hline & \multicolumn{2}{c}{ NNT (95\% CI) } \\
\cline { 2 - 3 } & SXB4.5g & SXB6g \\
\hline Pain VAS & $7(5$ to 18$)$ & $5(3$ to 7$)$ \\
$\geq 30 \%$ & $8(5$ to 23$)$ & $5(4$ to 8$)$ \\
$\geq 50 \%$ & $19(10$ to $\infty)$ & 11 (7 to 29$)$ \\
$\quad 280 \%$ & & \\
FIQ improvement & $6(4$ to 12$)$ & $4(3$ to 6$)$ \\
$\geq 14 \%$ & $5(4$ to 10$)$ & $4(3$ to 7$)$ \\
$\geq 30 \%$ &
\end{tabular}

FIQ, fibromyalgia impact questionnaire; NNT, number needed to treat; SXB4.5g, sodium oxybate $4.5 \mathrm{~g} / \mathrm{night}$; SXB6g, sodium oxybate $6 \mathrm{~g} / \mathrm{night}$; VAS, visual analogue scale.

\section{Tolerability and safety}

The overall incidence of AE was comparable for SXB $4.5 \mathrm{~g} / \mathrm{night}$ and SXB $6 \mathrm{~g} /$ night and higher than for placebo (table 4). Most $\mathrm{AE}$ were mild or moderate in severity. Treatment-emergent AE resulted in study discontinuation in $14.9 \%$ of SXB $4.5 \mathrm{~g} / \mathrm{night}$ subjects and $20.6 \%$ of SXB $6 \mathrm{~g} /$ night subjects versus $5.3 \%$ for placebo.

The most frequently reported $\mathrm{AE}$ ( $\geq 5 \%$ and twice the rate for placebo) were nausea, dizziness, vomiting, insomnia, anxiety, somnolence, fatigue, muscle spasms and peripheral oedema. Eight subjects experienced treatment-emergent serious $\mathrm{AE}$ (three in the placebo, two in the SXB $4.5 \mathrm{~g} /$ night and three in the SXB $6 \mathrm{~g} /$ night groups); of these, two were considered to be related to study treatment (vomiting in one SXB $4.5 \mathrm{~g} / \mathrm{night}$ subject and headache in one SXB 6 g/night subject). Weight loss was observed in the SXB-treated groups, with a mean (standard error) weight change from baseline of $-1.19(0.22) \mathrm{kg}$ in the SXB $6 \mathrm{~g} /$ night group and $-0.43(0.20) \mathrm{kg}$ in the SXB $4.5 \mathrm{~g} /$ night group compared with a mean weight gain of $0.43(0.16) \mathrm{kg}$ in the placebo group. There were no deaths. More subjects in the SXB groups discontinued the study due to an $\mathrm{AE}$ compared with placebo (14.9\% for SXB $4.5 \mathrm{~g} /$ night, $20.6 \%$ for SXB $6 \mathrm{~g} /$ night and $5.3 \%$ for placebo); the most frequent $\mathrm{AE}$ leading to discontinuation ( $\geq 3 \%$ and twice that for placebo) were nausea, headache, vomiting and anxiety (table 4).

\section{DISCUSSION}

This is the first international study that evaluated the efficacy and safety of SXB in a large number of fibromyalgia patients. The rationale for using SXB was based on its ability to improve restorative sleep and the observation that disturbed sleep can cause hyperalgesia in chronic pain conditions by dysregulation of the descending pain inhibitory pathways. ${ }^{31}$ It was hypothesised that the attainment of restorative sleep in SXB-treated patients should lead to a reduction in fibromyalgia-related pain and other symptoms by restoring a more normal balance in these pathways, which are known to be dysfunctional in fibromyalgia. ${ }^{32}$ The improvement in sleep quality as reflected by changes in JSS (a validated measure for sleep quality in the fibromyalgia population $)^{24}$ and the improvement in 'tired upon awakening', one of the items in the FIQ that assesses sleep disturbance, suggest that SXB may improve restorative sleep in fibromyalgia patients. In addition, SXB treatment resulted in a statistically significant reduction in pain and fatigue with both SXB dose groups compared with placebo. Reductions in pain were demonstrated at $30 \%$ or greater and at $50 \%$ or greater and, in the SXB $6 \mathrm{~g} /$ night group, at $80 \%$ or greater pain reduction. Particularly for those patients experiencing higher levels of pain reduction, these findings represent clinically important changes that extend
Table 4 Most frequent treatment-emergent AE and AE leading to discontinuation

\begin{tabular}{|c|c|c|c|c|}
\hline $\begin{array}{l}\text { Number (\%) of subjects } \\
\text { with } A E\end{array}$ & $\begin{array}{l}\text { Placebo } \\
\text { ( } n=188)\end{array}$ & $\begin{array}{l}\text { SXB4.5g } \\
(\mathrm{n}=194)\end{array}$ & $\begin{array}{l}\text { SXB6g } \\
(n=189)\end{array}$ & $\begin{array}{l}\text { Total } \\
(\mathrm{N}=571)\end{array}$ \\
\hline \multicolumn{5}{|l|}{$\begin{array}{l}\text { Most frequent } \\
A E \text { ( } \geq 5 \% \text { and twice } \\
\text { the placebo rate) }\end{array}$} \\
\hline Any AE & $126(67.0)$ & $146(75.3)$ & $156(82.5)$ & $428(75.0)$ \\
\hline Nausea & $16(8.5)$ & $37(19.1)$ & $40(21.2)$ & $93(16.3)$ \\
\hline Dizziness & $3(1.6)$ & $23(11.9)$ & $25(13.2)$ & $51(8.9)$ \\
\hline Vomiting & $6(3.2)$ & $10(5.2)$ & $16(8.5)$ & $32(5.6)$ \\
\hline Insomnia & $6(3.2)$ & $15(7.7)$ & $8(4.2)$ & $29(5.1)$ \\
\hline Anxiety & $3(1.6)$ & $10(5.2)$ & $15(7.9)$ & $28(4.9)$ \\
\hline Somnolence & $3(1.6)$ & $7(3.6)$ & $11(5.8)$ & $21(3.7)$ \\
\hline Fatigue & $4(2.1)$ & $6(3.1)$ & $11(5.8)$ & $21(3.7)$ \\
\hline Muscle spasms & $2(1.1)$ & $8(4.1)$ & $10(5.3)$ & $20(3.5)$ \\
\hline Oedema peripheral & $4(2.1)$ & $3(1.5)$ & $12(6.3)$ & $19(3.3)$ \\
\hline \multicolumn{5}{|l|}{$\begin{array}{l}\text { Most frequent AE leading } \\
\text { to discontinuation } \\
\text { ( } \geq 3 \% \text { and twice the } \\
\text { placebo rate) }\end{array}$} \\
\hline $\begin{array}{l}\text { Any AE leading to } \\
\text { discontinuation }\end{array}$ & $10(5.3)$ & $29(14.9)$ & $39(20.6)$ & $78(13.7)$ \\
\hline Nausea & $1(0.5)$ & $6(3.1)$ & $10(5.3)$ & $17(3.0)$ \\
\hline Headache & 0 & $4(2.1)$ & $8(4.2)$ & $12(2.1)$ \\
\hline Vomiting & $1(0.5)$ & $3(1.5)$ & $6(3.2)$ & $10(1.8)$ \\
\hline Anxiety & $1(0.5)$ & $1(0.5)$ & $6(3.2)$ & $8(1.4)$ \\
\hline
\end{tabular}

AE, adverse event; SXB4.5g, sodium oxybate $4.5 \mathrm{~g} / \mathrm{night}$; SXB6g, sodium oxybate $6 \mathrm{~g} /$ night.

beyond pain reduction and encompass a broad range of symptoms. The onset of pain reduction occurred relatively rapidly and was maintained during the 14-week trial in most patients. Tenderness, reflecting hyperalgesia and allodynia, a core domain to be assessed in all fibromyalgia clinical trials, ${ }^{10}$ was decreased, as seen by a statistically significant reduction in MTPS.

Improvement was not limited to pain, as multiple symptoms and general health, measured by the FIO total score and SF-36, were also improved. A reduction of $14 \%$ or greater in FIO, achieved by $62.6-70.8 \%$ of the SXB groups, is consistent with the MCID definition, ${ }^{33}$ whereas the reduction of $30 \%$ or greater in FIQ achieved by $50.0-55.1 \%$ of the SXB groups can be considered a moderate/good response. Moreover, the fibromyalgia syndrome composite score, which is a more stringent measure that includes pain, FIO and PGIC, was significantly improved for both SXB $4.5 \mathrm{~g} / \mathrm{night}$ and SXB $6 \mathrm{~g} / \mathrm{night}$ versus placebo. In addition, a significant improvement in the functional composite score following both SXB doses versus placebo was observed, even when it was based on a more stringent cut-off value for the SF-36 ( $\geq 6$; as established for fibromyalgia patients $)^{30}$ than the MCID (3-5). ${ }^{34}$

The estimated NNT for $50 \%$ or greater pain reduction for SXB $4.5 \mathrm{~g} /$ night and SXB $6 \mathrm{~g} /$ night, 8 and 5 , respectively, compare favourably with an NNT of 6.4 for duloxetine (combined 60 and $120 \mathrm{mg}$ doses) for a similar treatment period (12-13 weeks $)^{35}$ and are superior to the NNT of 16 for pregabalin 450 mg (the maximum recommended dose) for a 12 -week treatment period. ${ }^{36}$ This study is also the first to evaluate NNT for the improvement of multidimensional function (FIQ) and shows that four to six patients need to be treated to achieve clinically relevant improvements.

Several study limitations should be noted. There was a high rate of discontinuation; however, discontinuations in the current study were consistent with the $33-42 \%$ discontinuation rate in other fibromyalgia phase 3 clinical trials. ${ }^{1930} 37-42$ Another limitation, common to all clinical trials, is that the evaluated 
population may not necessarily be representative of clinical practice. Demographically, the characteristics of patients in the current study were what may be expected clinically ${ }^{43} 44$ and were comparable to study populations in clinical trials for the approved fibromyalgia agents (predominantly female, middle aged, Caucasian, overweight and with fibromyalgia symptoms for approximately 10 years). ${ }^{30} 35-40$

The results from this study, demonstrating the association of sleep quality restoration with the multidimensional improvements in fibromyalgia symptoms, are consistent with the longheld notion that non-restorative sleep may play a role in the pathophysiology of fibromyalgia ${ }^{12}$ and reinforce the recommendation that the restoration of sleep quality should be a therapeutic aim in fibromyalgia. ${ }^{10}$ However, this is a challenging goal as many current treatments, such as hypnotics and antidepressants, improve insomnia but may have limited effect on sleep quality and, in particular, non-refreshed sleep. ${ }^{45}$ It is possible that SXB may improve fibromyalgia symptoms by other as yet unidentified mechanisms, aside from an improvement in sleep quality. Further analysis and mechanistic studies will be required to explore these possibilities.

Contributors $\mathrm{MS}, \mathrm{RMB}$ and $\mathrm{EHC}$ collected or assembled data. $\mathrm{EHC}, \mathrm{RMB}, \mathrm{CL}$ $\mathrm{MS}, \mathrm{BAB}$ and $\mathrm{YGW}$ undertook or supervised analysis and interpretation of data. $\mathrm{CL}$ conducted statistical analysis. MS, RMB, EHC, BAB and YGW contributed to the writing of the manuscript. All authors had access to the data, contributed substantially to the writing of the report and reviewed and approved the final draft. MS had final responsibility for the decision to submit this manuscript for publication.

Acknowledgements The authors would like to thank the investigators and their patients for their participation in this study. A list of study investigators follows. Editorial assistance was provided by Jane Gorsline, PhD, and Kathleen Ryan. Graphical and formatting support was provided by the Curry Rockefeller Group, Tarrytown, New York, USA.

Funding This study and report was sponsored and funded by Jazz Pharmaceuticals, Inc.

Competing interests $\mathrm{MS}, \mathrm{RMB}$ and EHC are consultants to and have received research support from Jazz Pharmaceuticals for this study. MS has also acted as a consultant to Allergan and has been a consultant and participated on the speakers bureaux of Eli Lilly, Pierre Fabre Médicament, Pfizer and UCB. RMB has also acted as a consultant to Cypress Bioscience, Eli Lilly and Pfizer, and has received research support from Merck and Schwarz Pharma. BAB, YGW and CL are employees and stockholders of Jazz Pharmaceuticals. EHC has also acted as a consultant to and has been a member of the speakers' bureaux of Abbott Laboratories, Chugai Pharma, Eli Lilly, MSD, Pfizer, Pierre Fabre Médicament, Roche and UCB, and has been a consultant to Allergan, AstraZeneca, Boehringer Ingelheim, Chelsea Therapeutics, GlaxoSmithKline, Merrimack Pharmaceutical, Schering Plough, Synovate and UCB Celltech. His institution has received research support from Chelsea Therapeutics, Chugai Pharma, Jazz Pharmaceuticals, MSD, Pfizer, Roche and UCB. The lead/ corresponding author had final responsibility for the decision to submit this manuscript for publication.

Ethics approval This study was approved by the ethics committee or institutional review board of each study site.

\section{Patient consent Obtained.}

Study investigators: France: P Hatron, S Perrot, B Rioult, E Serra, N Cantagrel, M Lanteri-Minet, A Dumolard. Germany: R Alten, U Jaeger, G Neeck, F Petzke, M Spaeth, T Weiss, W Sohn, B Wiedeking, H Zug. Italy: L Bazzichi, P Sarzi Puttini. The Netherlands: M van de Laar, R van Seventer. Poland: J Brzezicki, A FilipowiczSosnowska, S Jeka, E Kucharz, W Samborski, M Brzosko. Spain: C Alegre, A Fernandez Nebro, F Francisco, J Gomez-Reino, V Poca, R Queiro, A Rodriguez de la Serna, J Vidal. UK: A Adebajo, A Bhalla, E Choy, D Walker, S Richards, P Taylor, K Adams. USA: P Alder, R DiGiovanni, AE Massey, E Ekman, N Feldman, J Fidelholtz, 0 Florete, HS Fung, W George, A Goldstein, D Haselwood, D Johnson, L Lavelle, B Long, P Manolukas, V Mehra, D Mehta, L Perez-Limonte, D Sikes, J Silverfield, M Tark, D Weiss, C Wiesenhutter, H Williams, J Winfield, K Hackshaw, G Forde, T Johnson, JK Schwab, M McNett, R Bennett, S Sitar, M Abeles, N Rosenthal, B Cleeremans, M Barber, R Nielsen, R Ziman, M Dempsey, M Colvard, M Liebowitz, J Greenwald, R Staud, A Ellenbogen, P Mease, E Walko, K Willingham, S Silverman, S Choi, J Borders, R Guthrie, T Swick, D Young, R Rauck, T Wade, T Smith, C Curtis, D Ferrera, T Sligh, L Sharp, S Flitman, S Cohen, M Hassman, JD Hudson, R Pucillo, M Hagen, M Dunn.

Provenance and peer review Not commissioned; externally peer reviewed

\section{REFERENCES}

1. Woolf AD, Zeidler H, Haglund U, et al. Musculoskeletal pain in Europe: its impact and a comparison of population and medical perceptions of treatment in eight European countries. Ann Rheum Dis 2004;63:342-7.

2. Okura K, Lavigne GJ, Huynh N, et al. Comparison of sleep variables between chronic widespread musculoskeletal pain, insomnia, periodic leg movements syndrome and control subjects in a clinical sleep medicine practice. Sleep Med 2008;9:352-61.

3. Lautenbacher S, Kundermann B, Krieg JC. Sleep deprivation and pain perception. Sleep Med Rev 2006;10:357-69.

4. Kundermann B, Spernal J, Huber MT, et al. Sleep deprivation affects thermal pain thresholds but not somatosensory thresholds in healthy volunteers. Psychosom Med 2004;66:932-7.

5. Roehrs T, Hyde M, Blaisdell B, et al. Sleep loss and REM sleep loss are hyperalgesic. Sleep 2006;29:145-51.

6. Moldofsky H. Rheumatic manifestations of sleep disorders. Curr Opin Rheumatol 2010;22:59-63.

7. Wolfe F, Smythe HA, Yunus MB, et al. The American College of Rheumatology 1990 criteria for the classification of fibromyalgia. Report of the Multicenter Criteria Committee. Arthritis Rheum 1990;33:160-72.

8. White LA, Birnbaum HG, Kaltenboeck A, et al. Employees with fibromyalgia: medical comorbidity, healthcare costs, and work loss. J Occup Environ Med 2008;50:13-24.

9. Branco JC, Bannwarth B, Failde I, et al. Prevalence of fibromyalgia: a survey in five European countries. Semin Arthritis Rheum 2010;39:448-53.

10. Mease P, Arnold LM, Choy EH, et al.; OMERACT Fibromyalgia Working Group. Fibromyalgia syndrome module at OMERACT 9: domain construct. J Rheumatol 2009;36:2318-29.

11. Moldofsky H. The significance of dysfunctions of the sleeping/waking brain to the pathogenesis and treatment of fibromyalgia syndrome. Rheum Dis Clin North Am 2009;35:275-83

12. Moldofsky H, Scarisbrick P, England R, et al. Musculosketal symptoms and non-REM sleep disturbance in patients with "fibrositis syndrome" and healthy subjects. Psychosom Med 1975; $\mathbf{3 7}: 341-51$

13. Davies KA, Macfarlane GJ, Nicholl Bl, et al. Restorative sleep predicts the resolution of chronic widespread pain: results from the EPIFUND study. Rheumatology (Oxford) 2008;47:1809-13.

14. Pardi D, Black J. Gamma-hydroxybutyrate/sodium oxybate: neurobiology, and impact on sleep and wakefulness. CNS Drugs 2006;20:993-1018.

15. Scharf MB, Hauck M, Stover R, et al. Effect of gamma-hydroxybutyrate on pain, fatigue, and the alpha sleep anomaly in patients with fibromyalgia. Preliminary report. J Rheumato/ 1998:25:1986-90.

16. Scharf MB, Baumann M, Berkowitz DV. The effects of sodium oxybate on clinical symptoms and sleep patterns in patients with fibromyalgia. J Rheumatol 2003; 30:1070-4

17. Russell IJ, Perkins AT, Michalek JE; Oxybate SXB-26 Fibromyalgia Syndrome Study Group. Sodium oxybate relieves pain and improves function in fibromyalgia syndrome: a randomized, double-blind, placebo-controlled, multicenter clinical trial. Arthritis Rheum 2009;60:299-309.

18. Moldofsky H, Inhaber NH, Guinta DR, et al. Effects of sodium oxybate on sleep physiology and sleep/wake-related symptoms in patients with fibromyalgia syndrome: a double-blind, randomized, placebo-controlled study. J Rheumatol 2010;37:2156-66.

19. Russell IJ, Holman AJ, Swick TJ, et al.; Sodium Oxybate 06-008 FM Study Group. Sodium oxybate reduces pain, fatigue, and sleep disturbance and improves functionality in fibromyalgia: results from a 14-week, randomized, double-blind, placebo-controlled study. Pain 2011;152:1007-17.

20. Netzer NC, Stoohs RA, Netzer CM, et al. Using the Berlin Questionnaire to identify patients at risk for the sleep apnea syndrome. Ann Intern Med 1999;131:485-91.

21 Xyrem (Sodium Oxybate) Oral Solution [prescribing information]. Palo Alto, CA: Jazz Pharmaceuticals, Inc. 2007.

22. Burckhardt CS, Clark SR, Bennett RM. The fibromyalgia impact questionnaire: development and validation. J Rheumatol 1991;18:728-33.

23. Jenkins CD, Stanton BA, Niemcryk SJ, et al. A scale for the estimation of sleep problems in clinical research. J Clin Epidemiol 1988;41:313-21.

24. Crawford BK, Piault EC, Lai C, et al. Assessing sleep in fibromyalgia: investigation of an alternative scoring method for the Jenkins Sleep Scale based on data from randomized controlled studies. Clin Exp Rheumatol 2010;28(6 Suppl 63):S100-9.

25. Ware JE Jr, Sherbourne CD. The MOS 36-item short-form health survey (SF-36) I. Conceptual framework and item selection. Med Care 1992;30:473-83.

26 The Euro0ol group. EuroOol - a new facility for the measurement of health-related quality of life. Health Policy 1990;16:199-208.

27. Weaver TE, Laizner AM, Evans LK, et al. An instrument to measure functional status outcomes for disorders of excessive sleepiness. Sleep 1997;20:835-43.

28. Okifuji A, Turk DC, Sinclair JD, et al. A standardized manual tender point survey. I. Development and determination of a threshold point for the identification of positive tender points in fibromyalgia syndrome. J Rheumatol 1997;24:377-83.

29 Guy W. ECDEU Assessment Manual for Psychopharmacology (revised). DHEW publication no. (ADM) 76-338. Rockville, MD: US Department of Health, Education, and Welfare 1976. 
30. Mease PJ, Clauw DJ, Gendreau RM, et al. The efficacy and safety of milnacipran for treatment of fibromyalgia. a randomized, double-blind, placebo-controlled trial. J Rheumato/ 2009;36:398-409.

31. Smith MT, Edwards RR, McCann UD, et al. The effects of sleep deprivation on pain inhibition and spontaneous pain in women. Sleep 2007:30:494-505.

32. Julien $\mathbf{N}$, Goffaux $\mathrm{P}$, Arsenault $\mathrm{P}$, et al. Widespread pain in fibromyalgia is related to a deficit of endogenous pain inhibition. Pain 2005;114:295-302.

33. Bennett RM, Bushmakin AG, Cappelleri JC, et al. Minimal clinically important difference in the fibromyalgia impact questionnaire. J Rheumato/ 2009;36:1304-11.

34. Samsa G, Edelman D, Rothman ML, et al. Determining clinically important differences in health status measures: a general approach with illustration to the Health Utilities Index Mark II. Pharmacoeconomics 1999;15:141-55.

35. Sultan A, Gaskell H, Derry S, et al. Duloxetine for painful diabetic neuropathy and fibromyalgia pain: systematic review of randomised trials. BMC Neurol 2008;8:29.

36. Straube S, Derry S, Moore RA, et al. Pregabalin in fibromyalgia - responder analysis from individual patient data. BMC Musculoskelet Disord 2010:11:150.

37. Clauw DJ, Mease P, Palmer RH, et al. Milnacipran for the treatment of fibromyalgia in adults: a 15-week, multicenter, randomized, double-blind, placebo-controlled, multiple-dose clinical trial. Clin Ther 2008;30:1988-2004.

38. Arnold LM, Russell IJ, Diri EW, et al. A 14-week, randomized, double-blinded, placebo-controlled monotherapy trial of pregabalin in patients with fibromyalgia. J Pain 2008;9:792-805.
39. Arnold LM, Lu Y, Crofford LJ, et al. A double-blind, multicenter trial comparing duloxetine with placebo in the treatment of fibromyalgia patients with or without major depressive disorder. Arthritis Rheum 2004;50:2974-84.

40. Arnold LM, Rosen A, Pritchett YL, et al. A randomized, double-blind, placebocontrolled trial of duloxetine in the treatment of women with fibromyalgia with or without major depressive disorder. Pain 2005;119:5-15.

41. Mease PJ, Russell IJ, Arnold LM, et al. A randomized, double-blind, placebo-controlled, phase III trial of pregabalin in the treatment of patients with fibromyalgia. J Rheumatol 2008;35:502-14.

42. Crofford LJ, Rowbotham MC, Mease PJ, et al.; Pregabalin 1008-105 Study Group. Pregabalin for the treatment of fibromyalgia syndrome: results of a randomized, double-blind, placebo-controlled trial. Arthritis Rheum 2005; 52:1264-73.

43. Häuser $\mathbf{W}$, Zimmer $\mathbf{C}$, Felde $\mathbf{E}$, et al. [What are the key symptoms of fibromyalgia? Results of a survey of the German Fibromyalgia Association]. Schmerz 2008;22:176-83.

44. Bennett RM, Jones J, Turk DC, et al. An internet survey of 2,596 people with fibromyalgia. BMC Musculoskelet Disord 2007:8:27.

45. Wolfe F, Clauw DJ, Fitzcharles MA, et al. The American College of Rheumatology preliminary diagnostic criteria for fibromyalgia and measurement of symptom severity. Arthritis Care Res (Hoboken) 2010:62:600-10. 